\title{
Substituição da Fibra de Vidro por Fibra de Bananeira em Compósitos de Polietileno de Alta Densidade. Parte 1. Avaliação Mecânica e Térmica
}

\author{
Thiago S. Gomes, Leila L. Y. Visconte, Elen B. A. V. Pacheco \\ Instituto de Macromoléculas Professora Eloisa Mano, UFRJ
}

Resumo: A utilização de resíduo de fibra natural em substituição à fibra de vidro foi avaliada. Foram estudados compósitos de polietileno de alta densidade, HDPE, e fibra de bananeira com 10, 20, 30 e 40\% (m/m) de fibra. Compósitos com fibra de vidro, mesma matriz polimérica e nas mesmas proporções, foram preparados para comparação. Os compósitos foram obtidos em extrusora dupla-rosca co-rotacional interpenetrante e os corpos de prova foram preparados por injeção. As propriedades mecânicas sob tração, flexão e impacto foram avaliadas. As propriedades térmicas foram analisadas por calorimetria diferencial de varredura (DSC) e análise termogravimétrica (TG). A incorporação de fibra de bananeira no HDPE resultou no aumento de cristalinidade do polímero. Houve, também, considerável aumento no grau de reforço mecânico nos compósitos pela incorporação da fibra natural. Foi possível comprovar a substituição da fibra de vidro pela fibra de bananeira em determinados percentuais, quando misturados ao HDPE, sem prejuízo às propriedades. A análise termogravimétrica dos compósitos mostrou que o início de degradação se deu numa faixa de temperatura intermediária entre a da fibra e a da matriz polimérica.

Palavras-chave: Fibra de bananeira, polietileno de alta densidade, compósitos.

\section{Mechanical and Thermal Behavior of Composites Based on High Density Polyethylene and Banana Tree Fiber}

\begin{abstract}
The use of banana tree fiber instead of glass fiber in polyethylene composites was evaluated. Composites of high density polyethylene with 10, 20, 30 and $40 \mathrm{wt}$ \% of banana fiber were investigated. For comparison, composites with glass fiber, with the same polymeric matrix and proportions, were prepared. The samples were produced using an intermeshing co-rotating twin-screw extruder and injection molding. The mechanical properties investigated were the tensile, flexural and impact resistances of the composite. Thermal analyses were carried out by differential scanning calorimetry (DSC) and thermogravimetry (TG). The incorporation of fiber resulted in an increase in the composite degree of crystallinity. A considerable increase in mechanical reinforcement was achieved by incorporation of banana fiber in the composites. Thus, the replacement of fiberglass by banana fiber is possible when the components are used in specific proportions. Thermogravimetric analysis of the composites showed intermediate degradation temperatures between the values for banana fiber and polymeric matrix.
\end{abstract}

Keywords: Banana fiber, high density polyethylene, composite.

\section{Introdução}

A utilização das fibras naturais como reforço tem conquistado a atenção da comunidade científica e das indústrias, como alternativa às fibras inorgânicas, apresentando vantagens como grande abundância e baixa massa específica ${ }^{[1]}$. Dentre as fibras vegetais mais usadas destacam-se as fibras de sisal, coco, curauá, bambu, pinus, bananeira, além de outras ${ }^{[2]}$. Estima-se que as plantações de bananeiras, no Brasil, sejam responsáveis pela ocupação de uma área de 500 mil hectares, sendo a segunda fruta mais cultivada no país ${ }^{[3]}$.

No entanto, fibras vegetais apresentam início de degradação em 200-220 ${ }^{\circ} \mathrm{C}^{[4]}$, sendo adequadas para reforçar polímeros que sejam processados até essa temperatura, como o polipropileno (PP), poli(cloreto de vinila) (PVC) e polietilenos de alta (HDPE) e de baixa (LDPE) densidades ${ }^{[5]}$. Para comparar o efeito desse reforço, propriedades mecânicas como resistência à tensão e módulo de elasticidade servem como base para avaliar o desempenho mecânico de diferentes materiais, bem como avaliar o efeito de fatores, tais como volume, orientação, dispersão da fibra na matriz polimérica, além da afinidade química entre fibra e matriz ${ }^{[6,7]}$.

No sentido de avaliar tais fatores, Yuan et al. ${ }^{[8]}$ preparam compósitos com diferentes tamanhos de fibra de madeira de carvalho $(125,180$ e $250 \mu \mathrm{m})$ utilizando a técnica de extrusão com dupla rosca seguida do processo de injeção, para a mistura do material e obtenção dos corpos de prova, respectivamente. Estudaram a influência do tamanho da fibra nos compósitos de poliolefinas (PP e HDPE). Houve um ganho nas propriedades mecânicas do compósito com o aumento do tamanho da fibra, passando de 125 para $180 \mu \mathrm{m}$. Porém, quando o tamanho da fibra passou de 180 para $250 \mu \mathrm{m}$, ocorreu um decréscimo na propriedade, evidenciando, assim, a existência de um tamanho ótimo para esse tipo de fibra ${ }^{[8]}$, para a obtenção de efeito mais positivo.

Como cada fibra apresenta diferentes propriedades e características morfológicas, Mueller e Krobjilowski ${ }^{[9]}$ compararam compósitos de polipropileno com as fibras de linho (Linum usitatissimum), cânhamo (Cannabis sativa), kenaf (Hibiscus cannabinus) e fibra de vidro, utilizando uma estrutura de sanduíche, dispondo as fibras de forma aleatória, sem trançamento dessas fibras, para a confecção do compósito. Os autores destacaram que, apesar do compósito com fibra de vidro possuir maior resistência à tração, quando as fibras vegetais eram utilizadas em maiores proporções no compósito com PP, elas se apresentavam como alternativa viável à substituição da fibra de vidro. 
Além desta observação, os autores concluíram que um maior tamanho dos poros de fibra deve resultar em melhor penetração do polímero no material durante o processo de compressão, portanto, um compósito com melhores propriedades mecânicas ${ }^{[9]}$.

Outra característica importante são as propriedades térmicas, fundamentais para a obtenção de um ciclo de processamento mais rápido e com a menor degradação possível da fibra natural ${ }^{[7]}$. Com base nisso, Araújo et al. ${ }^{[10]}$ avaliaram o processo de degradação térmica de um compósito de HDPE com $20 \%$ em massa de fibra de curauá (Ananas erectifolius), preparado em extrusora de dupla rosca co-rotante e interpenetrante, com e sem agentes de acoplamento. Os agentes de acoplamento, copolímero de etileno com acetato de vinila e HDPE graftizado com anidrido maleico, foram adicionados separadamente no percentual de $2 \%$ em massa. Baseados na curva de perda de massa dessa fibra, os autores observaram maior estabilidade térmica no compósito sem agente de acoplamento, porém todos os compósitos apresentaram dois estágios de degradação ${ }^{[10]}$.

Joseph et al. ${ }^{[11]}$ realizaram modificações químicas na fibra de sisal (Agave sisalana), utilizando o derivado de uretano do polipropileno glicol, o polipropileno modificado com anidrido maleico e o permanganato de potássio $\left(\mathrm{KMnO}_{4}\right)$, com a intenção de melhorar a adesão interfacial entre a fibra e a matriz. A mistura das fibras com o PP se deu em uma câmara de mistura e os percentuais da fibra se mantiveram em $20 \%$ em massa para todos os compósitos com fibra tratada. As amostras foram submetidas a uma análise termogravimétrica (TGA) com a finalidade de se observar a estabilidade térmica desses compósitos com a fibra natural. O tratamento dado a essas fibras resultou em sensível melhora nas propriedades de interface, alterando diretamente as propriedades de estabilidade térmica. Os autores atribuíram a melhoria na estabilidade térmica a uma boa interação entre a fibra e a matriz. Em relação ao comportamento térmico dos compósitos contendo fibras naturais obtidos por calorimetria diferencial de varredura (DSC), o que tem sido observado é que a temperatura de fusão $\left(\mathrm{T}_{\mathrm{m}}\right)$ permanece praticamente inalterada, enquanto a temperatura de cristalização $\left(\mathrm{T}_{\mathrm{cc}}\right)$ da matriz é deslocada para temperaturas maiores. Este comportamento indica que essa fibra natural exerceu um efeito nucleante sobre a matriz polimérica. Os compósitos contendo $30 \%$ em massa de fibras curtas de sisal apresentaram um aumento significativo de $8{ }^{\circ} \mathrm{C}$ frente ao PP puro. Para este sistema o grau de cristalinidade também aumentou ${ }^{[11]}$.

Assim, em vista do potencial de utilização de fibras naturais em compósitos poliméricos, neste artigo são apresentados resultados dos compósitos a base de HDPE e fibra de bananeira, variandose o percentual e o tamanho da fibra, bem como a temperatura de extrusão. $\mathrm{O}$ objetivo foi avaliar o efeito destas variáveis no balanço de propriedades mecânicas e térmicas, em relação aos compósitos com fibra de vidro.

\section{Experimental}

O HDPE utilizado foi fornecido pela empresa Ipiranga (RS). O HDPE apresentava índice de fluidez de 5,4 g/10 minutos na temperatura de $190{ }^{\circ} \mathrm{C} / 2,16 \mathrm{~kg}$, de acordo com a norma ASTM 1238-04. A fibra de bananeira utilizada nos compósitos foi fornecida pela empresa Coopfibra (RJ), localizada no município de Rio Bonito, RJ. A Fibra de Vidro EC10 4,5 952 foi fornecida pela empresa OCV Reinforcements Ltda, situada em Capivari-SP; constituída de fios picados, medindo $4,5 \mathrm{~mm}$ de comprimento e $10 \mu \mathrm{m}$ de diâmetro; foram produzidos com vidro tipo E, com tratamento químico superficial com composto epoxissilano.

As fibras naturais foram extraídas manualmente do pseudocaule de bananeiras do tipo prata sob a forma de tiras, previamente lavadas em solução de extrato pirolenhoso e secas em temperatura ambiente. Em uma unidade fabril, esse material tratado e seco foi desfibrado em equipamento constituído de lâminas para desagregar as tiras do pseudocaule da bananeira, sendo posteriormente triturado em moinho de martelo com malha de $1 \mathrm{~mm}$.

A distribuição granulométrica do material moído ocorreu em peneirador vibratório, com dispositivo para controle da frequência das vibrações e relógio automático. Foram utilizadas 3 peneiras (16, 20 e 40 mesh) para determinar a distribuição dos tamanhos das fibras de modo a limitar as dimensões máxima e mínima da fibra entre os valores $1,19 \mathrm{~mm}$ e $0,42 \mathrm{~mm}$. Para o processamento, as fibras foram previamente secas, permanecendo na estufa por 12 horas a $60{ }^{\circ} \mathrm{C}$ e armazenadas em dessecador até o momento de serem processadas na extrusora.

Foi determinada a umidade (ASTM D 1348, 1961) a fim de adequar o processamento da fibra na extrusora. Uma massa conhecida do material foi acondicionada em estufa à temperatura constante, com pesagem do material antes e após o processo de secagem. A determinação do teor de umidade foi realizada segundo a Equação 1. Foram avaliadas 5 amostras da fibra para cálculo da média aritmética das determinações.

$$
\text { Teor de umidade }(\%)=\frac{M_{u}-M_{s}}{M_{u}} \times 100
$$

Em que, $M_{u}=$ massa da amostra úmida; $M_{s}=$ massa da amostra seca.

Com o objetivo de executar o menor número de experimentos necessários e extrair o máximo de informação dos dados coletados, utilizou-se a análise de planejamento experimental completo $2^{3}$, sendo avaliado o grau de influência dos parâmetros de processamento (temperatura de processamento, percentual de fibra e tamanho da fibra) nas propriedades mecânicas (módulo de resistência à tração e flexão) com auxílio do programa STATISTICA ${ }^{\odot}$ 9.0. Depois de realizada essa avaliação, os parâmetros que não influenciaram no processo estudado foram fixados, variando-se apenas aquele que foi mais significativo para essas propriedades.

Os compósitos foram preparados em extrusora dupla-rosca co-rotacional interpenetrante marca Teck Tril modelo DCT20, com $20 \mathrm{~mm}$ de diâmetro e $\mathrm{L} / \mathrm{D}=36$. O perfil de temperaturas no barril foi de $150{ }^{\circ} \mathrm{C}$ na primeira zona e $170{ }^{\circ} \mathrm{C}$ nas demais zonas e no cabeçote, com rotação das roscas em $300 \mathrm{rpm}$. Durante o processamento, o polímero foi introduzido no sistema através do funil principal, sendo fundido e homogeneizado na primeira zona de mistura da rosca. A fibra de bananeira (FB) foi dosada na extrusora por meio de alimentador lateral, com o polímero já fundido. $\mathrm{O}$ equipamento operou com uma vazão de $4 \mathrm{~kg} / \mathrm{h}$.

Após extrusão e granulação, corpos de prova para a caracterização dos compósitos foram obtidos por injeção em injetora marca Arburg Allrouder, modelo 270S 400-170. O perfil de temperatura empregado foi de 150 a $180{ }^{\circ} \mathrm{C}$, para a perfeita plastificação do material extrusado, com temperatura no molde de $60{ }^{\circ} \mathrm{C}$, mantida por um termorregulador a óleo. A velocidade (vazão) de injeção foi de $30 \mathrm{~cm}^{3} / \mathrm{s}$, a comutação para recalque por volume de $95 \%$, a pressão de recalque 1000 bar por 4 segundos e o tempo de resfriamento no molde de 30 segundos.

Foram avaliadas as propriedades mecânicas de resistências à tração (ASTM D 638-03), à flexão (ASTM D 790-03) e ao impacto (ASTM D 256-06). Analisaram-se também o teor de umidade (ASTM D 1348-61) e o de lignina presentes na fibra de bananeira, através de uma extração pelo método Klason ${ }^{[12]}$.

Foram avaliadas ainda as estabilidades térmicas das fibras de bananeira e dos compósitos contendo 20 e $40 \%$ em massa de fibra. A análise foi realizada sob atmosfera de oxigênio, com velocidade de $10{ }^{\circ} \mathrm{C} / \mathrm{min}$ e com faixa de aquecimento compreendida entre 30 e $700{ }^{\circ} \mathrm{C}$. As amostras foram submetidas ao ensaio calorimétrico 
em um calorímetro diferencial de varredura (DSC), sob atmosfera de nitrogênio, a uma faixa de temperatura de $20{ }^{\circ} \mathrm{C}$ a $170{ }^{\circ} \mathrm{C}$, com uma taxa de aquecimento de $10{ }^{\circ} \mathrm{C} / \mathrm{min}$. Para o cálculo de cristalinidade relativa, o valor de $\Delta \mathrm{H}^{\circ}$ padrão, considerando o HDPE $100 \%$ cristalino, foi de $288 \mathrm{~J} / \mathrm{g}^{[13]}$.

\section{Resultados e Discussão}

A distribuição mássica resultante do processo de peneiramento é mostrada na Figura 1.

O tamanho de partícula escolhido para a preparação dos compósitos foi restringido entre 1,19 e $0,42 \mathrm{~mm}$, devido às limitações técnicas durante o processamento, uma vez que as fibras maiores se aglomeram no sistema de alimentação da extrusora, formando chumaços que prejudicam a vazão de alimentação dessas cargas.

O teor de lignina da fibra de bananeira, obtido experimentalmente foi de $21,1+3,1 \%$ em massa. Porém, há grande divergência quanto ao valor real do teor de lignina na fibra da bananeira. Segundo Oliveira $^{[14]}$, o teor estaria entre 33 e $37 \%$ em massa, de acordo com a parte do pseudocaule trabalhada. Joseph et al. ${ }^{[15]}$ encontraram valores próximos de $5 \%$ em massa de lignina para esse tipo de fibra.

Entretanto, não se deve atribuir essa grande variação nos valores do teor de lignina somente à diferença entre as espécies. De acordo com Kollmann e Côté[16], a fibra lignocelulósica, por ser um material

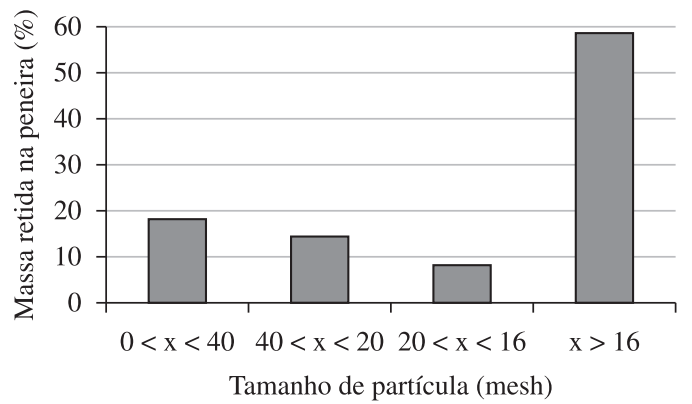

Figura 1. Fração percentual em massa das partículas de fibra de bananeira retidas na peneira versus faixa de tamanho das partículas. heterogêneo, pode apresentar grande variação na composição química, até mesmo em se tratando de uma mesma espécie. Segundo Silva et al. ${ }^{[17]}$, as variações nas composições químicas, físicas e anatômicas da celulose ocorrem em função, principalmente, da idade, de fatores genéticos e ambientais.

O teor de umidade da fibra de bananeira foi determinado através da secagem da amostra do material em estufa até massa constante. As fibras de bananeira constituem materiais hidrofílicos devido à presença de grupamentos hidroxilas em sua estrutura ${ }^{[18]}$. O teor de umidade médio encontrado para a fibra de bananeira foi de $11,4+0,3 \%$ em massa. Deve-se destacar que esse valor foi obtido após beneficiamento e secagem ao ar livre na cooperativa. $\mathrm{O}$ valor encontra-se na mesma faixa de umidade relatada para a madeira, que fica entre $10-18 \%$ em massa ${ }^{[19]}$.

Como essas fibras naturais apresentavam teor de umidade superior a $1 \%$ em massa, foi necessária a secagem em estufa para garantir um processamento eficiente através da extrusão. A matriz polimérica utilizada foi uma poliolefina, que possui características hidrofóbicas e que, portanto, não absorve água, sendo, assim, dispensada de secagem.

Nas Tabelas 1 e 2 foram calculadas as significâncias estatísticas dos fatores analisados pelo planejamento de experimento, no qual foram considerados como fatores estatisticamente significativos somente aqueles que apresentam os limites dos níveis de confiança de $-95 \%$ a $95 \%$ com mesmo sinal, ou seja, garantindo que não apresentam o valor zero. Foi possível observar que estes fatores relevantes apresentam valor- $p$ inferior a 0,05 . Os parâmetros significativos estão em negrito nas Tabelas 1 e 2 .

Observando-se as respostas analisadas, mostradas nas Tabelas 1 e 2, o fator percentual de fibra foi relevante estatisticamente para ambas as propriedades (Módulos de tração e de flexão). A interação entre os fatores (temperatura de processamento, percentual de fibra e tamanho da fibra) também apresentou significado estatístico. Isso prova que, para o processamento desse compósito, a análise dos fatores de maneira isolada pode não ser suficiente para explicar fielmente os fenômenos ocorridos e, consequentemente, pode não

Tabela 1. Dados para significado estatístico de resposta do módulo de elasticidade somente com fatores relevantes.

\begin{tabular}{|c|c|c|c|c|c|c|}
\hline Fator & Efeito & Erro puro & Teste $\mathbf{t}$ & $\mathbf{p}$ & $-95 \%$ & $+95 \%$ \\
\hline M & 592,4 & 3,0 & 199,5 & 0,00002 & 579,6 & 605,1 \\
\hline 1 & 93,0 & 7,0 & 13,4 & 0,00556 & 63,0 & 123,0 \\
\hline 3 & 357,5 & 7,0 & 51,3 & 0,00038 & 327,5 & 387,5 \\
\hline $1 * 2$ & 161,5 & 7,0 & 23,2 & 0,00185 & 131,5 & 191,5 \\
\hline $1 * 3$ & $-135,0$ & 7,0 & $-19,4$ & 0,00265 & $-165,0$ & $-105,0$ \\
\hline $2 * 3$ & 86,0 & 7,0 & 12,3 & 0,00649 & 56,0 & 116,0 \\
\hline $1 * 2 * 3$ & 14,5 & 7,0 & 2,1 & 0,17278 & $-15,5$ & 44,5 \\
\hline
\end{tabular}

Obs. M - média, 1 - temperatura de processamento, 2 - tamanho da fibra, 3 - percentual de fibra.

Tabela 2. Dados para significado estatístico de resposta do módulo de resistência à flexão somente com fatores relevantes.

\begin{tabular}{|c|c|c|c|c|c|c|}
\hline Fator & Efeito & Erro puro & $t(3)$ & $\mathbf{p}$ & $-95 \%$ & $+95 \%$ \\
\hline M & 1460,5 & 29,6 & 49,4 & 0,00041 & 1333,2 & 1587,7 \\
\hline 1 & $-75,8$ & 69,4 & $-1,1$ & 0,38876 & $-374,2$ & 222,7 \\
\hline 2 & 211,3 & 69,4 & 3,1 & 0,09300 & $-87,2$ & 509,7 \\
\hline 3 & 1004,8 & 69,4 & 14,5 & 0,00473 & 706,3 & 1303,2 \\
\hline $1 * 2$ & 248,3 & 69,4 & 3,6 & 0,06996 & $-50,2$ & 546,7 \\
\hline $1 * 3$ & $-7,3$ & 69,4 & $-0,1$ & 0,92628 & $-305,7$ & 291,2 \\
\hline $2 * 3$ & 82,8 & 69,4 & 1,2 & 0,35516 & $-215,7$ & 381,2 \\
\hline $1 * 2 * 3$ & 471,8 & 69,4 & 6,8 & 0,02094 & 173,3 & 770,2 \\
\hline
\end{tabular}

M - média, 1 - temperatura de processamento, 2 - comprimento da fibra, 3 - percentual de fibra. 
justificar os resultados obtidos para os ensaios mecânicos de tração e flexão que foram avaliados.

Pela Tabela 1, a única interação que não apresentou significado estatístico foi a interação entre todos os fatores. Todas outras interações apresentam respostas significativas no módulo de elasticidade. No caso da Tabela 2, os únicos fatores com significado estatístico são o fator percentual de fibra e a interação entre todos os fatores.

Os valores experimentais encontrados para o módulo sob tração são mostrados na Figura 2. É possível observar que a adição da fibra de bananeira ao HDPE conduz a um acréscimo no módulo de elasticidade de aproximadamente 326, 530, 727 e $732 \%$ nos compósitos com 10, 20, 30 e 40\% (m/m) de carga, respectivamente, tomando como base o polietileno puro, que apresentou um valor de módulo elástico de $105 \mathrm{MPa}$.

Um fato interessante a se observar na Figura 2 é a formação de um platô em torno de $30 \%(\mathrm{~m} / \mathrm{m})$ de fibra de bananeira. Os compósitos de fibra de bananeira, quando comparados aos de fibra de vidro, apresentam um desempenho menor. Porém, o compósito com $10 \%(\mathrm{~m} / \mathrm{m})$ de fibra de vidro apresentou valor de propriedade de módulo elástico próximo ao compósito com $20 \%$ (m/m) de fibra de bananeira.

Comparando os resultados com os de outros autores que utilizaram fibras lignocelulósicas, observou-se, neste trabalho, um ganho acentuado de propriedades em relação a outros trabalhos. Santos ${ }^{[12]}$ reporta um ganho de módulo de apenas $54 \%$ em relação ao HDPE puro, utilizando como agente de reforço a serragem de cedro. $\mathrm{Amim}^{[20]}$, utilizando a fibra de coco verde, obteve uma melhora de aproximadamente $94 \%$ em relação ao material sem carga de reforço.

Os resultados do módulo de elasticidade sob flexão para as formulações de fibra de bananeira e fibra de vidro estão expressos na Figura 3.

Analisando-se a Figura 3, nota-se um acréscimo no módulo de flexão promovido pelo aumento do teor da fibra, tanto de vidro quanto de bananeira. Na formulação contendo $10 \%(\mathrm{~m} / \mathrm{m})$ de fibra de bananeira, praticamente não houve alteração em relação ao HDPE puro.

Já nas formulações contendo 20, 30 e $40 \%(\mathrm{~m} / \mathrm{m})$ de fibra de bananeira, houve aumento de aproximadamente $62 \%, 147 \%$ e $164 \%$, respectivamente, em relação ao polímero puro. O HDPE puro apresentou módulo elástico de flexão de $942 \pm 39 \mathrm{MPa}$. Os resultados mostram que a adição da carga de fibra celulósica contribui significativamente para o aumento do módulo.

Segundo Santos ${ }^{[12]}$, esse fato sugere que o aumento da concentração de fibra de lignocelulósica reduz a mobilidade das cadeias da matriz polimérica, levando ao aumento no módulo sob flexão dos compósitos. Isso ocorre devido à diminuição da capacidade de deformação do material quando submetido à flexão, afetando a propriedade de maneira inversa ao alongamento na ruptura dos materiais.

No caso da fibra de vidro, observa-se que o aumento de módulo sob flexão se deu de maneira muito mais intensa com uma melhoria de 71,217 e $381 \%$ para os percentuais de 10,20 e $30 \%(\mathrm{~m} / \mathrm{m})$ de fibra de vidro, respectivamente.

Comparando-se a fibra de bananeira com a de vidro, é possível afirmar que, para percentuais próximos a $10 \%(\mathrm{~m} / \mathrm{m})$ de fibra de vidro, a de bananeira pode atuar plenamente como um substituto dessa fibra sintética quando usada no teor de $20 \%(\mathrm{~m} / \mathrm{m})$.

Correlacionando-se com outros trabalhos que utilizaram fibras lignocelulósicas, foram observados ganhos de propriedade muito próximos. Santos ${ }^{[12]}$, utilizando $30 \%(\mathrm{~m} / \mathrm{m})$ de serragem de cedro, obteve um ganho de módulo de flexão de $162 \%$ em relação ao HDPE puro utilizado, valor muito próximo aos $164 \%$ obtidos neste trabalho com $40 \%(\mathrm{~m} / \mathrm{m})$ de fibra de bananeira. Araújo ${ }^{[10]}$, utilizando $30 \%(\mathrm{~m} / \mathrm{m})$ da fibra curauá, obteve um ganho no módulo de flexão de $150 \%$ em relação à matriz de HDPE puro.

A Figura 4 mostra os resultados de resistência ao impacto dos compósitos com fibras de bananeira e de vidro. A adição de fibra de bananeira ao HDPE aumentou a resistência ao impacto do compósito, em relação ao polietileno puro, diferentemente do que aconteceu com a fibra de vidro. É possível observar que, no caso

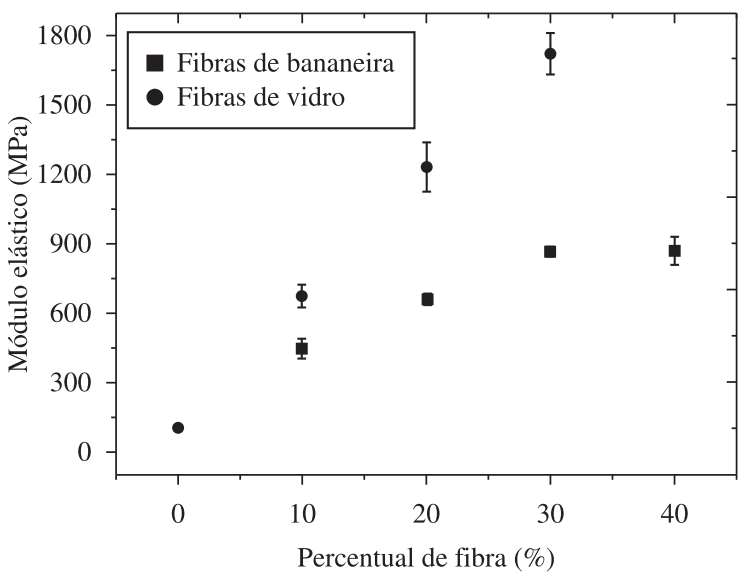

Figura 2. Módulo elástico do HDPE com fibras de bananeira e de vidro em diferentes percentuais em massa.

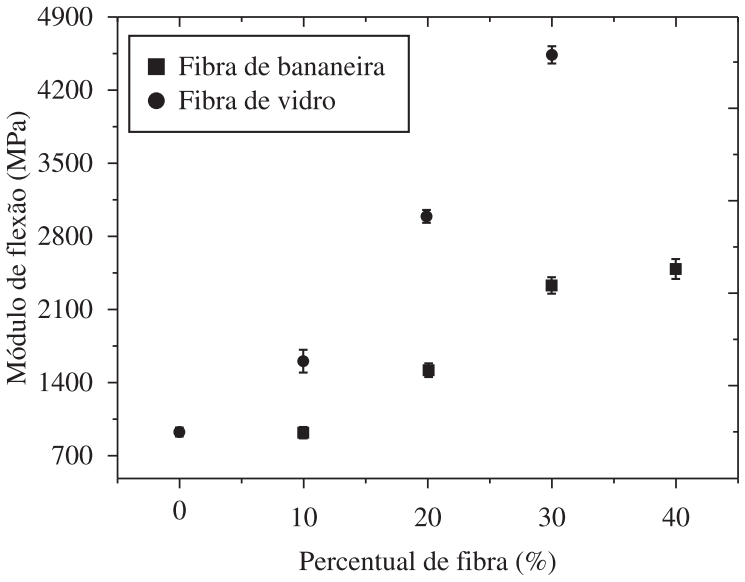

Figura 3. Módulo elástico sob flexão do HDPE com fibras de bananeira e de vidro em diferentes percentuais em massa.

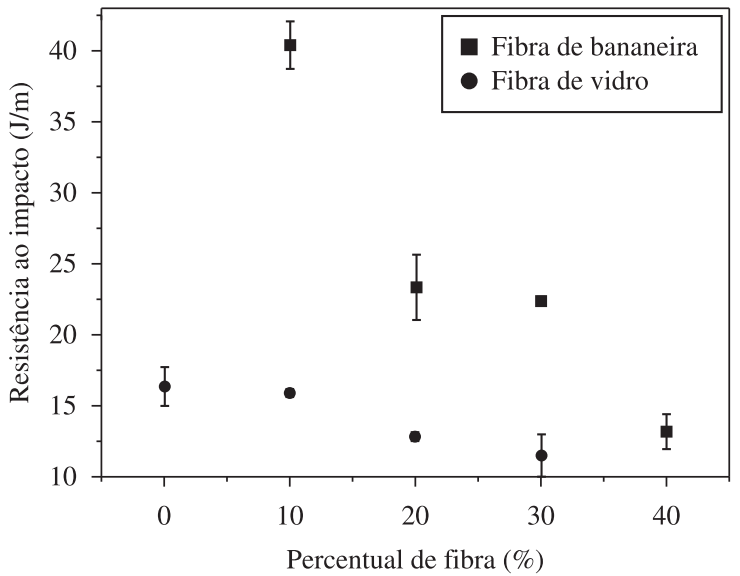

Figura 4. Resistência ao impacto do HDPE com fibras de bananeira e vidro em diferentes percentuais em massa. 
da fibra de bananeira, com $10 \%(\mathrm{~m} / \mathrm{m})$ de fibra há uma melhora em $247 \%$ em relação ao HDPE puro, que possui resistência ao impacto de $16,4 \pm 1,3 \mathrm{~J} / \mathrm{m}$.

Para os demais teores de fibra de bananeira, de 20 e $30 \%$ $(\mathrm{m} / \mathrm{m})$, há uma melhora discreta, de 142 e $136 \%$, na propriedade de resistência ao impacto em relação ao HDPE puro.

Somente a composição com $40 \%(\mathrm{~m} / \mathrm{m})$ de fibra de bananeira apresentou uma redução, em relação ao polímero puro, de aproximadamente $20 \%$. Segundo Balzer et al. ${ }^{[2]}$, essa diminuição de resistência em concentrações mais elevadas de fibras pode ocorrer, provavelmente, devido à baixa afinidade entre a matriz e o reforço.

Devido ao caráter hidrofílico da celulose presente na fibra de bananeira, a interface de adesão com a matriz polimérica (HDPE) fica enfraquecida, afetando a dispersão das fibras, que tendem a formar aglomerados por ligações de hidrogênio, aumentando a absorção de umidade da fibra gerando um inchamento do compósito e a presença de vazios (poros) na interface do material, resultando em uma diminuição nas propriedades de resistência mecânica ${ }^{[21]}$.

No caso dos compósitos com fibra de vidro, houve um decréscimo na resistência ao impacto para todas as composições. Esse efeito, segundo Diaz e Feltran ${ }^{[22]}$, pode ser justificado por uma concentração de tensões que a fibra de vidro exerce na matriz polimérica, sendo um forte indício da pouca adesão entre fibra de vidro e matriz ocorrida nos compósitos.

Araújo $^{[10]}$, em seus estudos, não variou o percentual de fibra na preparação dos compósitos para o ensaio de impacto, mantendo sempre a fração de $20 \%(\mathrm{~m} / \mathrm{m})$ de fibra de curauá. Com esse teor, foi observada uma redução de $30 \%$ na propriedade em relação ao HDPE puro.

A Figura 5 apresenta a curva termogravimétrica obtida da fibra de bananeira, na qual é possível observar a perda percentual de massa da amostra com o aumento da temperatura.
Analisando-se a curva da fibra de bananeira, observam-se duas perdas de massas, que são representadas pelas inflexões da curva de TG. A perda de massa inicial, que ocorre em aproximadamente $45{ }^{\circ} \mathrm{C}$, foi atribuída à perda de materiais voláteis presentes na fibra celulósica. Esses voláteis podem ser umidade, terpenos, álcoois, ésteres, aldeídos, cetonas, ácidos orgânicos, hidrocarbonetos alifáticos e fenóis ${ }^{[23]}$

A segunda perda de massa da amostra analisada, atribuída à degradação dos componentes da fibra de bananeira, ficou compreendida entre $225^{\circ} \mathrm{C}$ e $400{ }^{\circ} \mathrm{C}$, representando uma redução significativa, de quase $60 \%(\mathrm{~m} / \mathrm{m})$. Isso indica o limite de estabilidade térmica da fibra nessa faixa de temperatura. Contudo, acima dessa faixa de temperatura, a perda de massa continuou a acontecer, porém de forma menos intensa. A amostra alcançou aproximadamente $76 \%$ de redução de sua massa a $700{ }^{\circ} \mathrm{C}$.

Observa-se que a degradação do HDPE puro iniciou em aproximadamente $400^{\circ} \mathrm{C}$. Os compósitos apresentaram temperaturas intermediárias entre a da poliolefina e a da fibra de bananeira, sendo que quanto maior o percentual de fibra na composição menor a temperatura de início da degradação térmica, pois a fibra degrada a temperatura mais baixa que a da matriz do polímero. Quanto maior a proporção de fibra, maior será seu efeito sobre a estabilidade do compósito.

A Tabela 3 apresenta os resultados obtidos a partir dos ensaios de DSC. Foram utilizados os dados relativos ao segundo aquecimento e segundo resfriamento. É possível observar pelos dados que a temperatura de fusão $\left(\mathrm{T}_{\mathrm{m}}\right)$ não se altera e que não há variação expressiva na temperatura de cristalização no resfriamento $\left(\mathrm{T}_{\mathrm{cc}}\right)$. Porém, com a adição da fibra de bananeira, houve um acréscimo no grau de cristalinidade $\left(\mathrm{X}_{c}\right)$.

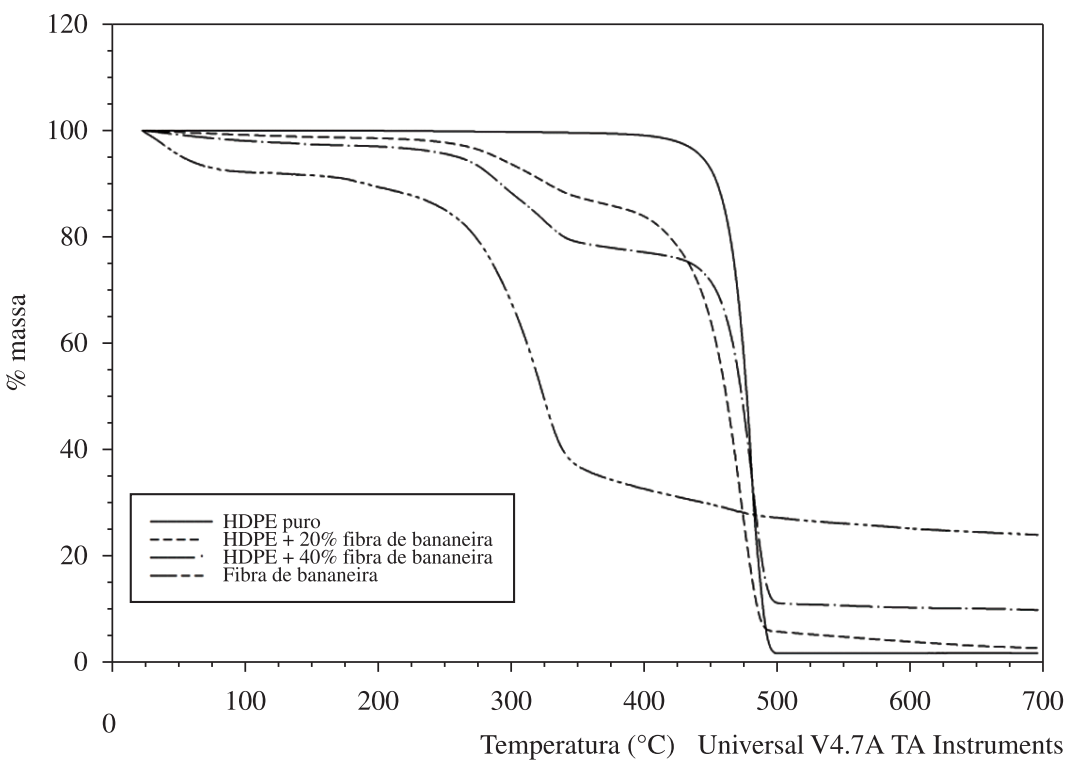

Figura 5. Curva termogravimétrica do HDPE puro, da fibra de bananeira e dos compósitos de HDPE com 20 e $40 \%$ (m/m) de fibra de bananeira.

Tabela 3. Temperaturas de fusão e cristalização e grau de cristalinidade de HDPE e misturas de HDPE/fibra de bananeira nas proporções 80/20 e 60/40\% $(\mathrm{m} / \mathrm{m})$.

\begin{tabular}{lccc}
\hline \multicolumn{1}{c}{ Amostra } & $\mathbf{T}_{\mathrm{m}}\left({ }^{\circ} \mathbf{C}\right)$ & $\mathbf{T}_{\mathrm{cc}}\left({ }^{\circ} \mathbf{C}\right)$ & $\mathbf{X}_{\mathrm{c}}(\boldsymbol{\%})$ \\
\hline HDPE puro & 131 & 116 & 59 \\
HDPE $/ 20 \%(\mathrm{~m} / \mathrm{m})$ fibra de bananeira & 131 & 115 & 65 \\
HDPE/40\% $(\mathrm{m} / \mathrm{m})$ fibra de bananeira & 131 & 116 & 73 \\
\hline
\end{tabular}

$\mathrm{T}_{\mathrm{m}}$ - Temperatura de fusão; $\mathrm{T}_{\mathrm{cc}}-$ Temperatura de cristalização no resfriamento; $\mathrm{X}_{\mathrm{c}}-$ Grau de cristalinidade. 
A temperatura de fusão cristalina pode ser influenciada pela presença da carga celulósica ${ }^{[24]}$, contudo este efeito não foi observado nas misturas estudadas.

$\mathrm{O}$ aumento de $\mathrm{X}_{\mathrm{c}}$ para os compósitos com fibra sugere que as fibras podem ter atuado como agentes nucleantes. Segundo Carreira $^{[25]}$, sabe-se que a presença de cargas ou impurezas em polímeros leva à cristalização, com formação de cristais em torno das fibras, resultante da adsorção de segmentos moleculares na superfície de partículas estranhas ao sistema, caracterizando um ponto de nucleação. Sendo assim, é possível que as fibras tenham atuado como agentes nucleantes, aumentando, assim, o grau de cristalinidade do compósito.

\section{Conclusão}

Por meio do planejamento de experimentos fatorial foi possível concluir que o fator de maior influência nas propriedades mecânicas avaliadas é o teor de fibra no compósito. Sendo assim, com o auxílio desse estudo estatístico otimizou-se o tempo de máquina e reduziu-se o número de formulações, maximizando a análise ao utilizar apenas o fator de influência para obtenção das melhores formulações para o compósito. Dentre as propriedades mecânicas estudadas, as que mais sofreram influência da adição da fibra de bananeira foi o módulo elástico sob tração, o módulo elástico sob flexão e a resistência ao impacto que alcançaram um aumento de aproximadamente $732 \%, 164 \%$ e $135 \%$, respectivamente, em relação ao polímero puro, tornando-se uma alternativa ao uso da fibra de vidro. Observou-se que na estabilidade térmica dos compósitos o início de degradação ocorreu em temperaturas intermediárias entre a fibra de bananeira (temperatura menor) e o HDPE (temperatura maior), quando os polímeros sozinhos. A cristalinidade do material aumentou, sugerindo a atuação das fibras como agente nucleante. Porém, por não terem ocorrido variações na temperatura de fusão cristalina, o tamanho dos domínios cristalinos não sofreu alteração na matriz. Conclui-se que a fibra de bananeira pode substituir a de vidro em misturas com o HDPE, principalmente se utilizada em $20 \%$ $(\mathrm{m} / \mathrm{m})$, quando se desejam boas propriedades de flexão e impacto.

\section{Referências Bibliográficas}

1. Esmeraldo, M. A. - "Preparação de novos compósitos suportados em matriz de fibra vegetal/natural", Dissertação de Mestrado, Universidade Federal do Ceará, Brasil (2006).

2. Balzer, P. S.; Vicente, L. L.; Briesemeister, R.; Becker, D.; Soldi, V.; Rodolfo Junior, A.; Feltran, M. B. - Polímeros, 17 (2007).

3. SEBRAE. - "Estudo de mercado: Banana", Série Mercado (2007).

4. Gassan, A. K. \& Bledski, J. - Prog. Polym. Sci., 24, p.221 (1999).

5. Malkapuram, R.; Kumar, V.; Negi, Y. S. J. - Reinf. Plast. Compos., 28, p.1169 (2009). http://dx.doi.org/10.1177/0731684407087759

6. Bonelli, C. M. C.; Elzubair, A.; Suarez, J. C. M.; Mano, E. B. - Polímeros, 15, p.256 (2005). http://dx.doi.org/10.1590/S010414282005000400009

7. Canevarolo Junior, S. V. - "Ciência dos Polímeros", Artliber, São Paulo (2002).
8. Yuan, Q.; Wu, D.; Gotama, J.; Bateman, S. - J. Thermoplast. Compos. Mater., 21, p.195 (2008).

9. Mueller, D. H.; Krobjilowski, A. - J. Ind. Textil., 33 (2003).

10. Araújo, J. R.; Waldman, W. R., De Paoli, M. A. - Polym. Degrad. Stab., 93, p.1770 (2008). http://dx.doi.org/10.1016/j. polymdegradstab.2008.07.021

11. Joseph, P. V.; Joseph, K.; Thomas, S.; Pillai, C. K. S.; Prasad, V. S.; Groeninckx, G.; Sarkissova, M. - Composites Part A., 34, p. 253 (2003). http://dx.doi.org/10.1016/S1359-835X(02)00185-9

12. Santos, F. A. - "Estudo de misturas de HDPE e serragem de cedro para obtenção de madeira plástica", Dissertação de Mestrado, Universidade Federal do Rio de Janeiro, Brasil (2008).

13. Khonakdar, H. A., Morshedian, J.; Wagenknecht, U.; Jafari, S. H. - Polymer, 44, p.4301 (2003). http://dx.doi.org/10.1016/S00323861(03)00363-X

14. Oliveira, I. T. D. - "Avaliação mecânica de compósitos de polietileno de alta densidade (pead) e vermiculita". Dissertação de Mestrado. Universidade Federal do Rio de Janeiro, Brasil (2007).

15. Joseph, A., Sreekala M. S., Oomen, Z., Koshy, P., Thomas, S. A. - Compos. Sci. Technol., 62, p.1857 (2002). http://dx.doi. org/10.1016/S0266-3538(02)00098-2

16. Kollmann, F. F. P.; Côté, W. A. - "Principles of wood science and technology", vol.1, Solid Wood, Springer-Verlag, Nova Iorque (1984).

17. Silva, R.; Haraguchi, S. K.; Muniz, E. C.; Rubira, A. F. - Quím. Nova, 32, p.661 (2009). http://dx.doi.org/10.1590/S0100-40422009000300010

18. Ishizaki, M. H.; Visconte, L. L. Y.; Furtado, C. R. G.; Leite, M. C. A. M.; Leblanc, J. L. - Polímeros, 16, p.182 (2006). http://dx.doi. org/10.1590/S0104-14282006000300006

19. Yamaji, F. M. - "Produção de compósito plástico-madeira a partir de resíduos da indústria madeireira”, Tese de doutorado, Universidade Federal do Paraná, Brasil (2004).

20. Amim, P. R. P. - "Estudo de misturas de HDPE e fibra de coco como mecanismo de desenvolvimento limpo para utilização em madeira plástica”, Dissertação de Mestrado, Universidade Federal do Rio de Janeiro, Brasil (2006).

21. Ashori, A. - Bioresour. Technol., 99, p.4661 (2008). PMid:18068352. http://dx.doi.org/10.1016/j.biortech.2007.09.043

22. Feltran, M. B.; Diaz, F. R. V. - Polímeros, 17, p.276 (2007). http:// dx.doi.org/10.1590/S0104-14282007000400005

23. Liu, H.; Wuq, Q.; Zhang, Q. - Bioresour. Technol., 100, p.6088 (2009). PMid:19574041. http://dx.doi.org/10.1016/j.biortech.2009.05.076

24. Pasquini, D.; Teixeira, E. M.; Curvelo, A. A. S.; Belgacem, M. N.; Dufresne, A. - Compos. Sci. Technol, 68, p.193 (2008). http://dx.doi. org/10.1016/j.compscitech.2007.05.009

25. Carreira, L. G. - "Misturas poliméricas PET/PC reforçadas com fibras de vidro curtas”, Dissertação de Mestrado, Universidade Federal do Rio de Janeiro, Brasil (2009). 